CLINICAL STUDY

\title{
Universal screening detects two-times more thyroid disorders in early pregnancy than targeted high-risk case finding
}

\author{
Jiri Horacek ${ }^{1}$, Sylvie Spitalnikova ${ }^{1}$, Blanka Dlabalova ${ }^{2}$, Eva Malirova ${ }^{2}$, Jaroslav Vizda $^{2}$, Ioannis Svilias ${ }^{1}$, \\ Jitka Cepkova ${ }^{1}$, Catherine Mc Grath ${ }^{1}$ and Jaroslav Maly ${ }^{1}$ \\ Departments of ${ }^{1}$ Internal Medicine and ${ }^{2}$ Nuclear Medicine, Faculty of Medicine and University Hospital in Hradec Kralove, Charles University in Prague, \\ Sokolska 581, 50005 Hradec Kralove, Czech Republic
}

(Correspondence should be addressed to J Horacek; Email: horacek@fnhk.cz)

\begin{abstract}
Objective: Screening of thyroid disorders in pregnancy has been controversial. Recent recommendations favour targeted high-risk case finding, though this approach may miss a significant number of those affected. We aimed to assess the prevalence of accepted high-risk criteria in women with autoimmune thyroiditis and/or hypothyroidism detected from universal screening in an iodinesufficient population.

Design: In 400 non-selected women in the 9-11th gestational week, thyroid-related tests were performed, and those with abnormalities were offered consultation.

Methods: TSH was determined by IRMA, and the upper cut-off value for screening was set at $3.5 \mathrm{mIU} / \mathrm{l}$. For free thyroxine $\left(\mathrm{FT}_{4}\right)$ and thyroperoxidase antibodies (TPO-Ab), RIAs were used, with cut-offs of $<10 \mathrm{pmol} / \mathrm{l}$ and $>50 \mathrm{IU} / \mathrm{ml}$ respectively. Endocrinological consultation included Doppler ultrasonography and was aimed to confirm autoimmune thyroiditis and/or hypothyroidism. The prevalence of consensus high-risk criteria was assessed.

Results: Among the 400 women, 65 (16.3\%) had $\geq 1$ abnormality: higher TSH was found in $10.3 \%$, lower $\mathrm{FT}_{4}$ in $2 \%$ and positive TPO-Ab in $8.3 \%$. Fifty-one women were examined and followed up. Levo- $\mathrm{T}_{4}$ treatment was initiated in 49 women for autoimmune thyroiditis (in 42), hypothyroidism (in 34) or both (in 27). Only 22 (45\%) of 49 treated women fulfilled $\geq 1$ high-risk criterion: most commonly family history (31\%), history of miscarriage or preterm delivery $(14 \%)$ and personal history $(8 \%)$.

Conclusions: Over half $(55 \%)$ of pregnant women with abnormalities suggestive of autoimmune thyroiditis and/or hypothyroidism would be missed if only those with high-risk criteria were examined. A more extensive screening of thyroid autoimmunity and dysfunction seems warranted.
\end{abstract}

European Journal of Endocrinology 163 645-650

\section{Introduction}

Chronic autoimmune thyroiditis, often manifested only by thyroid peroxidase (TPO-Ab) and/or thyroglobulin antibodies (Tg-Ab), is associated with a two- to fourfold increase in miscarriage rate and premature deliveries (1-3). Moreover, a pregnant woman with positive TPO-Ab has a $30-52 \%$ chance of developing post-partum thyroiditis (PPTD) (4, 5). In iodinesufficient regions, chronic autoimmune thyroiditis is also the most common cause of hypothyroidism, often at subclinical levels, that may be further aggravated by the increased need for thyroid hormones in pregnancy (6). The lack of thyroid hormones, even subclinical, is associated not only with an increased risk of obstetrical complications but also with an impaired neuropsychological development of the child $(7,8)$.
As hypothyroidism is easily treated by levothyroxine $\left(\mathrm{L}-\mathrm{T}_{4}\right)$ replacement and equally the same treatment may effectively reduce the risk of obstetrical complications also in euthyroid women with positive TPO-Ab (2), active screening for thyroid disease in pregnancy seems reasonable (9) and cost effective $(10,11)$. Nevertheless, the suggested range of screened population has remained controversial. The recent Endocrine Society Clinical Practice Guideline recommends targeted case finding by measurement of TSH in women with specified high risk for thyroid disease (12).

Vaidya et al. (13) directly compared the outcome of universal screening with that of case finding based on a similar set of risk factors (14), and reported that the latter approach would miss about a third of pregnant women with hypothyroidism. This finding may support the idea of a more general screening (15). Furthermore, 
they focused on hypothyroidism, but they also found women with positive TPO-Ab in $8 \%$ of their population, a similar fraction as observed in other studies, with most of them (73\%) being euthyroid (13). As positive TPO-Ab confer risks (of obstetric complications and PPTD) independent of hypothyroidism, this variable seems worth including in the screening panel $(9,10)$.

The yield and cost effectivity of screening are dependent not only on the range of the screened population but also on the variables used and on assay cut-offs. Often the reference range (RR) provided by the manufacturer is not suitable for women in early pregnancy, and the cut-offs should be adjusted $(16,17)$.

Here, we present a pilot study of screening for autoimmune thyroiditis and/or hypothyroidism in non-selected pregnant women using TSH, TPO-Ab and free $\mathrm{T}_{4}\left(\mathrm{FT}_{4}\right)$ demonstrating that less than half of those positively screened would have been identified if only those fulfilling the recommended criteria for targeted case finding were examined.

\section{Subjects and methods}

Regional gynaecologists were offered the addition of three thyroid-related variables into the prenatal screening panel in the 9-11th week of pregnancy offered to all pregnant women in our study population. They explained the reasons for thyroid testing to the pregnant women and the possible participation of an endocrinologist in the follow-up, and received written informed consent from the pregnant women. The project was approved by the appropriate ethics committee. Funding was sufficient for the recruitment of 400 women.

The serum samples were sent to the same laboratory responsible for the standard prenatal screening and were assayed for TSH, $\mathrm{FT}_{4}$ and TPO-Ab. TSH (RR, 0.15-5.0 mIU/l) was measured by IRMA (Immunotech, Beckman Coulter, Prague, Czech Republic). $\mathrm{FT}_{4}$ (RR, $11-23 \mathrm{pmol} / \mathrm{l})$ and TPO-Ab $(\mathrm{RR}<12 \mathrm{IU} / \mathrm{ml})$ were determined by RIA (Immunotech, Beckman Coulter). The inter-assay coefficient of variation (CV) was $5.5 \%$ for $\mathrm{TSH}, 8.4 \%$ for $\mathrm{FT}_{4}$ and $7.5 \%$ for $\mathrm{TPO}-\mathrm{Ab}$.

The recommended cut-off values for screening in pregnancy have been a matter of controversy $(16,17)$. It is generally accepted that TSH levels in the first trimester are lower; indeed, a recent study from our country suggested $3.67 \mathrm{mIU} / \mathrm{l}$ as the upper limit of normal in this population (17). We invited those with
TSH $>3.5 \mathrm{mIU} / \mathrm{l}$ to visit our endocrine clinic. In women with TSH below the RR $(0.15 \mathrm{mIU} / \mathrm{l})$, only those with increased $\mathrm{FT}_{4}$ or clinical symptoms of hyperthyroidism were considered for endocrine consultation, but no such case was found in our sample. As for low $\mathrm{FT}_{4}$, women with values $<10 \mathrm{pmol} / \mathrm{l}$ were invited for consultation. The selected value for positivity of TPO-Ab is probably the most complicated aspect, clearly method dependent, and the manufacturer's cut-off values may not be appropriate (17). Based on our previous experience with the method, we decided to invite those with $\mathrm{TPO}-\mathrm{Ab}>50 \mathrm{IU} / \mathrm{ml}$.

The endocrine consultation included a detailed personal and family history and physical examination, with an explicit attention to the risk factors defined by the consensus guidelines (12). Moreover, thyroid ultrasonography (Toshiba Nemio, $9 \mathrm{MHz}$ linear transducer, with power Doppler imaging) was performed. The thyroid gland volume was estimated, and the structure was assessed for homogeneity, echogenicity and vascularity, especially valuable in cases of suspicion of chronic autoimmune thyroiditis, on a modified semiquantitative scale: 1 - normal, 2 - borderline, 3 - suspect and 4 - typical $(18,19)$. If necessary (due to borderline screening values), the tests for screening were repeated together with further assays: free triiodothyronine (RIA, Immunotech, Beckman Coulter, RR, 2.5-5.7 pmol/l, CV, $6.4 \%$ ) and $\mathrm{Tg}-\mathrm{Ab}$ (RIA, Immunotech, Beckman Coulter, RR, $<100 \mathrm{IU} / \mathrm{ml}, \mathrm{CV}, 10.4 \%)$.

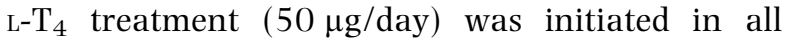
women with clearly positive TPO-Ab (>50 IU/ml) and suspect or typical sonographic pattern together strongly suggestive of chronic autoimmune thyroiditis (2). As optimal TSH in pregnancy seems to be in low normal values (20), the treatment was targeted to TSH $<2.5 \mathrm{mIU} / \mathrm{l}$ (16) and, if necessary, the dose was adjusted on a subsequent visit 4 weeks later. In addition, the treatment was initiated in those without a clear indication of chronic autoimmune thyroiditis but with TSH consistently $>2.5 \mathrm{mIU} / \mathrm{l}$.

\section{Results}

The distribution of three screening variables in our sample is shown in Table 1. Among 400 pregnant women, TSH $>3.5 \mathrm{mIU} / \mathrm{l}$ was found in $41(10.3 \%)$, $\mathrm{FT}_{4}<10 \mathrm{pmol} / \mathrm{l}$ in $8(2 \%)$ and TPO-Ab $>50 \mathrm{IU} / \mathrm{ml}$ in $33(8.3 \%)$ women; a total of $65(16.3 \%)$ had at least one

Table 1 Distribution of the screening variables in the screened sample of women in the 9-11th week of pregnancy $(n=400)$.

\begin{tabular}{lccccccccc}
\hline Percentile & $\mathbf{2 . 5}$ & $\mathbf{5}$ & $\mathbf{1 0}$ & $\mathbf{2 5}$ & $\mathbf{5 0}$ & $\mathbf{7 5}$ & $\mathbf{9 0}$ & $\mathbf{9 5}$ & $\mathbf{9 7 . 5}$ \\
\hline $\mathrm{TSH}(\mathrm{mlU} / \mathrm{l})$ & 0.12 & 0.27 & 0.51 & 0.95 & 1.70 & 2.53 & 3.52 & 4.23 & 5.72 \\
$\mathrm{FT}_{4}(\mathrm{pmol} / \mathrm{l})$ & 10.3 & 10.8 & 11.5 & 12.5 & 13.9 & 15.3 & 16.6 & 17.5 & 18.2 \\
$\mathrm{TPO}-\mathrm{Ab}(\mathrm{IU} / \mathrm{ml})$ & 4.6 & 5.3 & 6.0 & 7.0 & 8.4 & 10.2 & 25.3 & 177.6 & 403.7 \\
\hline
\end{tabular}

$\mathrm{FT}_{4}$, free thyroxine; TPO-Ab, thyroperoxidase antibodies. 
abnormality. After exclusion of five women already treated for autoimmune thyroiditis (and followed by their endocrinologists), the remaining women were offered endocrine consultation.

Fifty-one positively screened women were examined in our clinic and followed up. In 42 (82\%) women, chronic autoimmune thyroiditis was confirmed by ultrasonography and antibodies; of them 27 (64\%) also had TSH $>2.5 \mathrm{mIU} / \mathrm{l}$, suggestive of relative thyroid insufficiency. In addition, seven women had consistently higher TSH without the typical pattern of autoimmune thyroiditis. In all the 49 women with consistent abnormalities $(96 \%), \mathrm{L}^{-} \mathrm{T}_{4}$ treatment was initiated. Typically (in 41 , i.e. $84 \%$ ) the dose of $50 \mu \mathrm{g} /$ day was enough to maintain their TSH levels $<2.5 \mathrm{mIU} /$, and no case of overdose (TSH $<0.15 \mathrm{mIU} / \mathrm{l}$ ) was found on follow-up.

The women were also assessed according to ten accepted high-risk criteria (Table 2). Of the 49 positively screened women indicated for $\mathrm{L}_{-} \mathrm{T}_{4}$ treatment, there were no risk factors in 27 (i.e. 55\%, 95\% confidence interval (CI), 40-69\%) women. Moreover, in a well-defined subgroup of 42 women with autoimmune thyroiditis, 21 women ( $50 \%$, CI 34-66\%) had no risk factors.

Clustering of risk factors was even less common as only six women had two of them, and none had three or more risk factors.

The most promising risk factors included positive family history (present in 31\%), history of miscarriage or preterm delivery (14\%) and positive personal history $(8 \%)$. Determining the history of other autoimmune disorders and a history or presence of goitre were not productive. In general, the presence of goitre was rare as the largest sonographically measured thyroid volume was $21 \mathrm{ml}$. None of the remaining five risk factors was observed in our sample.

Of other items of personal history, which were not included in the consensus guideline criteria, it was the history of allergy that seemed to show some positive prognostic value, being positive in 14 of 49 women (29\%), a proportion similar to the best of the consensus risk factors.

Table 2 Prevalence of consensus guideline risk factors (ref. (23)) among positively screened and levothyroxine-treated pregnant women $(n=49)$.

\begin{tabular}{lc}
\hline Consensus guideline risk factor & Occurrence (\%) \\
\hline Personal history of a thyroid disorder & $4(8 \%)$ \\
Family history of a thyroid disorder & $15(31 \%)$ \\
Goitre & $1(2 \%)$ \\
History of positive thyroid antibodies & $0(0 \%)$ \\
Symptoms/signs of thyroid hypo/hyperfunction & $0(0 \%)$ \\
History of type 1 diabetes mellitus & $0(0 \%)$ \\
History of other autoimmune disorders & $1(2 \%)$ \\
Infertility & $0(0 \%)$ \\
History of head/neck irradiation & $0(0 \%)$ \\
History of miscarriage or preterm delivery & $7(14 \%)$ \\
None of them & $27(55 \%)$ \\
\hline
\end{tabular}

\section{Discussion}

In our sample of pregnant women with clear abnormalities suggestive of autoimmune thyroiditis and/or thyroid insufficiency, and indicated for treatment, over half $(55 \%)$ would be missed if only those with high-risk criteria were examined.

This proportion was even higher than that reported by Vaidya et al. (13), who arrived at similar conclusions, though they used a different design, namely, they concentrated on hypothyroid women (defined as TSH $>4.2 \mathrm{mIU} / \mathrm{l}$ ), and they did not consider TPO-Ab positivity. Moreover, they compared their yield with previous (slightly different) consensus criteria (14). They observed that 'only' one-third of hypothyroid women would be missed when just consensus criteria were used.

In our approach, we focused on early detection of autoimmune thyroiditis because of higher risk of various obstetrical complications as well as of PPTD and hypothyroidism (1-5). Therefore, ultrasonography was also used to confirm the diagnosis. Ultrasonography was performed by an experienced endocrinologist. There is the possibility of bias in this operation since ultrasound was performed after the laboratory results were available and the women were invited for consultation. However, this was the same for all the women invited for consultation, and by eliminating operator dependency, we maintained consistency over sonographic interpretation within the group.

The value of ultrasonography in this area is increasing. For example, Premawardhana et al. (19) showed useful predictive value of the combination of thyroid status, TPO-Ab and ultrasonography (the same triad as used in our study) in autoimmune PPTD. They showed that the hypothyroid form of PPTD, high TPO-Ab levels and a hypoechogenic ultrasound pattern lead to a high risk (relative risk, 32) of long-term thyroid dysfunction. Thus, early screening may again help in identifying those women for follow-up.

Therefore, we consider a more extensive, and probably universal, screening of thyroid autoimmunity and thyroid dysfunction in pregnancy to be the desired end point. In addition, it may also enable earlier identification of potentially serious problems in women without clear-cut risk factors, and since the treatment is relatively cheap and easy, this approach may be cost effective (10, 11). Indeed, as the awareness of these problems is spreading among gynaecologists (21), there is increasing tendency for more extensive screening (22). The recent large randomised study by Negro et al. (23) brought rather controversial results. While in the overall sample, universal screening compared with case finding did not result in a decrease in adverse obstetrical and neonatal outcomes, in the low-risk group, there was a clear improvement in the early detected and treated women. The editorial published in the same issue (24) comments on this apparent discrepancy and 
points out that treating the detected cases in high-risk groups in both arms of the study became 'dilutive' to the ultimate analysis. As there is no doubt that the high-risk group should be investigated anyway, the finding that the low-risk group would also benefit from testing and treatment is clearly supportive of universal screening.

The disadvantages of the screening include the cost and some maternal anxiety. The two available costeffective analyses $(10,11)$ took only the potential decrease in IQ of the children into consideration and still regarded the screening as cost effective. Our own experience with maternal anxiety was rather reassuring; in many pregnant women, there was no real anxiety (just interest), and a humane and professional approach, with adequate explanation, printed information and a hot line for further consultation, relieved any anxiety in the rest of the group.

While universal screening is gaining increasing support (24), the methods of screening, i.e. the variables measured and their cut-off values, are more controversial (16). In addition, the yield of screening may be influenced by regional differences, namely, by iodine sufficiency (25).

As for the variables, TPO-Ab seems to be particularly useful because it may allow for early detection of autoimmune thyroiditis, enabling appropriate treatment (2) and long-term follow up. In our sample, all 30 women with TPO-Abs $>50 \mathrm{IU} / \mathrm{ml}$ in screening and observed in our endocrine clinic also had sonographic patterns suggestive of autoimmune thyroiditis. The cutoff value for screening may be a problem; using the manufacturer's upper limit (usually not specific for pregnant women) may inadequately increase the number of positively screened and decrease the specificity. Springer et al. (17) using a different assay found $143 \mathrm{kU} / \mathrm{l}$ as a more adequate decision value for endocrine consultation than the manufacturer's cut-off value of $60 \mathrm{kU} / \mathrm{l}$. We also used an even stricter value of $50 \mathrm{IU} / \mathrm{ml}$ instead of the manufacturer's cut-off of $12 \mathrm{IU} / \mathrm{ml}$, and sonography confirmed that positively screened women indeed had autoimmune thyroiditis. However, looking at the distribution (Table 1), $25 \mathrm{IU} / \mathrm{ml}$ might have been more appropriate, thus indicating seven $(2 \%)$ more women for endocrine consultation. Clearly, the cut-off value for screening must be method dependent and population dependent, and should reflect the trade-off between sensitivity and specificity.

Similar considerations apply to the upper limit of TSH. It is generally agreed that TSH levels are lower in early pregnancy (6), and it appears that lower values are also more desirable for the pregnancy outcome $(16,20)$, but there is no generally accepted decision value for screening. Again, it should be method specific and population specific, and the cut-off values previously reported for hypothyroidism range from 5.2 to $2.0 \mathrm{mIU} / \mathrm{l}(2,8,13,14,17,26-29)$. Based on our previous experience (unpublished) that a value of $2.5 \mathrm{mIU} / \mathrm{l}$ brings too many false positives that are subsequently excluded from intervention when a combination of clinical history, (repeat) laboratory findings and ultrasonography is used, we selected $3.5 \mathrm{mIU} / \mathrm{l}$ as the screening cut-off value for TSH. In our sample of 400 pregnant women, this value is close to the 90 th percentile (Table 1), bringing about $10 \%$ of the cohort into further consideration. Among the 339 women with negative TPO-Ab $(\leq 12 \mathrm{IU} / \mathrm{ml}$, i.e. within the manufacturer's RR), this value lies between the 92nd and 93rd percentiles. We believe that the use of a screening target of $3.5 \mathrm{mIU} / \mathrm{l}$ and a treatment target of $2.5 \mathrm{mIU} / \mathrm{l}$ in women identified as having autoimmune thyroiditis provides a satisfactory return.

We also used $\mathrm{FT}_{4}$ as one of the screening variables in this study. Unlike TSH, it is not generally recommended for screening (12). In accordance with this, $\mathrm{FT}_{4}$ was much less effective in selecting women from our sample for endocrine consultation. Isolated $\mathrm{FT}_{4}$ abnormality (with TSH and TPO-Ab normal) was only found in 4 of $65(6 \%)$ positively screened women, and none of them was actually seen in our clinic, so they did not influence our conclusions. However, as isolated hypothyroxinaemia (with normal TSH in the range $0.15-2.0 \mathrm{mIU} / \mathrm{l}$ ) was associated with delayed mental and motor functions (8-10 points on the mental and motor scales at the age of 1 and 2 years, ref. (8)), this has made many researchers start to include $\mathrm{FT}_{4}$ into the testing battery. Interestingly, the preliminary data from the Controlled Antenatal Thyroid Screening Study, so-called CATS study (9), showed that "utilising both parameters (i.e. TSH and $\mathrm{FT}_{4}$ ) results in two abnormal pregnant populations - namely, about half with a low $\mathrm{T}_{4}$ and an equal number with a high TSH, with very few having both a low $\mathrm{T}_{4}$ and a high TSH'. The authors suggest that the former pattern may be related to iodine deficiency, while the latter to autoimmune thyroiditis (being also associated with TPO-Ab). Although iodine sufficiency was not specifically tested in our sample, we assume a generally satisfactory iodine status, as was recently demonstrated in our country in a population study using urinary iodine concentration and sonographically measured thyroid volume (30). Moreover, the thyroid volume in our sample (median $11 \mathrm{ml}$, interquartile range 9-13 ml) was not significantly different from that in the respective age and gender population subgroup (31). So iodine sufficiency may also explain the lower proportion of isolated hypothyroxinaemia in our cohort. On the other hand, removing $\mathrm{FT}_{4}$ from the screening panel may be inappropriate in those countries where iodine deficiency continues to be a problem. As with the other variables, the cut-off value selected may also prove to be controversial.

In summary, limitation of thyroid testing in early pregnancy only to women with generally accepted high-risk factors would miss a significant proportion (in our sample over half) of those indicated for endocrine care. More comprehensive screening of thyroid autoimmunity and dysfunction seems warranted. TPO-Ab 
and TSH (and possibly $\mathrm{FT}_{4}$ ) are best suited for this purpose, but their screening cut-off values should be a matter of further research, in terms of sensitivity and specificity.

\section{Declaration of interest}

The authors declare that there is no conflict of interest that could be perceived as prejudicing the impartiality of the research reported.

\section{Funding}

This work was supported by the General Health Insurance Company, Czech Republic and by Czech Ministry of Health (research project MZO 00179906).

\section{References}

1 Stagnaro-Green A \& Glinoer D. Thyroid autoimmunity and the risk of miscarriage. Best Practice and Research. Clinical Endocrinology and Metabolism 200418 167-181. (doi:10.1016/ j.beem.2004.03.007)

2 Negro R, Formoso G, Mangieri T, Pezzarossa A, Dazzi D \& Hassan H. Levothyroxine treatment in euthyroid pregnant women with autoimmune thyroid disease: effect on obstetrical complications. Journal of Clinical Endocrinology and Metabolism 200691 2587-2591. (doi:10.1210/jc.2005-1603)

3 Poppe K, Velkeniers B \& Glinoer D. The role of thyroid autoimmunity in fertility and pregnancy. Nature Clinical Practice. Endocrinology and Metabolism 20084 394-405. (doi:10.1038/ ncpendmet0846)

4 Muller AF, Drexhage HA \& Berghout A. Postpartum thyroiditis and autoimmune thyroiditis in women of childbearing age: recent insights and consequences for antenatal and postnatal care. Endocrine Reviews 200122 605-630. (doi:10.1210/er.22.5.605)

5 Roti E \& Uberti E. Post-partum thyroiditis - a clinical update. European Journal of Endocrinology 2002146 275-279. (doi:10. 1530/eje.0.1460275)

6 Glinoer D. The regulation of thyroid function in pregnancy: pathways of endocrine adaptation from physiology to pathology. Endocrine Reviews 199718 404-433. (doi:10.1210/er.18.3.404)

7 Haddow JE, Palomaki GE, Allan WC, Williams JR, Knight GJ, Gagnon J, O'Heir CE, Mitchell ML, Hermos RJ, Waisbren SE, Faix JD \& Klein RZ. Maternal thyroid deficiency during pregnancy and subsequent neuropsychological development of the child. New England Journal of Medicine 1999341 549-555. (doi:10.1056/ NEJM199908193410801)

8 Pop VJ, Brouwers EP, Vader HL, Vulsma T, van Baar AL \& de Vijlder JJ. Maternal hypothyroxinaemia during early pregnancy and subsequent child development: a 3-year follow-up study. Clinical Endocrinology 200359 282-288. (doi:10.1046/j.13652265.2003.01822.x)

9 Lazarus JH \& Premawardhana LDKE. Screening for thyroid disease in pregnancy. Journal of Clinical Pathology $2005 \mathbf{5 8} 449-452$. (doi:10.1136/jcp.2004.021881)

10 Dosiou C, Sanders GD, Araki SS \& Crapo LM. Screening pregnant women for autoimmune thyroid disease: a cost-effectiveness analysis. European Journal of Endocrinology 2008158 841-851. (doi:10.1530/EJE-07-0882)

11 Thung SF, Funai EF \& Grobman WA. The cost-effectiveness of universal screening in pregnancy for subclinical hypothyroidism. American Journal of Obstetrics and Gynecology 2009200 267.e1-267.e7. (doi:10.1016/j.ajog.2008.10.035)

12 Abalovich M, Amino N, Barbour LA, Cobin RH, De Groot LJ, Glinoer D, Mandel SJ \& Stagnaro-Green A. Management of thyroid dysfunction during pregnancy and postpartum: an Endocrine Society clinical practice guideline. Journal of Clinical Endocrinology and Metabolism 200792 S1-S47. (doi:10.1210/jc.2007-0141)
13 Vaidya B, Anthony S, Bilous M, Shields B, Drury J, Hutchison S \& Bilous R. Detection of thyroid dysfunction in early pregnancy: universal screening or targeted high-risk case finding? Journal of Clinical Endocrinology and Metabolism $2007 \mathbf{9 2}$ 203-207. (doi:10.1210/jc.2006-1748)

14 Surks MI, Ortiz E, Daniels GH, Sawin CT, Col NF, Cobin RH, Franklyn JA, Hershman JM, Burman KD, Denke MA, Gorman C, Cooper RS \& Weissman NJ. Subclinical thyroid disease: scientific review and guidelines for diagnosis and management. Journal of the American Medical Association 2004291 228-238. (doi:10. 1001/jama.291.2.228)

15 Brent GA. Editorial: diagnosing thyroid dysfunction in pregnant women: is case finding enough? Journal of Clinical Endocrinology and Metabolism 200792 39-41. (doi:10.1210/jc. 2006-2461)

16 Mandel SJ. Spencer CA \& Hollowell JG. Are detection and treatment of thyroid insufficiency in pregnancy feasible? Thyroid 200515 44-53. (doi:10.1089/thy.2005.15.44)

17 Springer D, Zima T \& Limanova Z. Reference intervals in evaluation of maternal thyroid function during the first trimester of pregnancy. European Journal of Endocrinology $2009 \mathbf{1 6 0}$ 791-797. (doi:10.1530/EJE-08-0890)

18 Marcocci C, Vitti P, Cetani F, Catalano F, Concetti R \& Pinchera A. Thyroid ultrasonography helps to identify patients with diffuse lymphocytic thyroiditis who are prone to develop hypothyroidism. Journal of Clinical Endocrinology and Metabolism 199172 209-213. (doi:10.1210/jcem-72-1-209)

19 Premawardhana LD, Parkes AB, Ammari F, John R, Darke C, Adams H \& Lazarus JH. Postpartum thyroiditis and long-term thyroid status: prognostic influence of thyroid peroxidase antibodies and ultrasound echogenicity. Journal of Clinical Endocrinology and Metabolism 200085 71-75. (doi:10.1210/jc. 85.1.71)

20 Benhadi N, Wiersinga WM, Reitsma JB, Vrijkotte TGM \& Bonsel GJ. Higher maternal TSH levels in pregnancy are associated with increased risk for miscarriage, fetal or neonatal death. European Journal of Endocrinology 2009160 985-991. (doi:10.1530/EJE08-0953)

21 Gaertner R. Thyroid diseases in pregnancy. Current Opinion in Obstetrics and Gynecology 200921 501-507. (doi:10.1097/GCO. Ob013e328332a 836)

22 Haddow JE, McClain MR, Palomaki GE, Kloza EM \& Williams J. Screening for thyroid disorders during pregnancy: results of a survey in Maine. American Journal of Obstetrics and Gynecology 2006194 471-474. (doi:10.1016/j.ajog.2005.07.055)

23 Negro R, Schwartz A, Gismondi R, Tinelli A, Mangieri T \& Stagnaro-Green A. Universal screening versus case finding for detection and treatment of thyroid hormonal dysfunction during pregnancy. Journal of Clinical Endocrinology and Metabolism 2010 95 1699-1707. (doi:10.1210/jc.2009-2009)

24 Alexander EK. Here's to you, baby! A step forward in support of universal screening of thyroid function during pregnancy. Journal of Clinical Endocrinology and Metabolism $2010 \mathbf{9 5}$ 1575-1577. (doi:10.1210/jc.2010-0155)

25 Moleti M, Lo Presti VP, Mattina F, Mancuso A, De Vivo A, Giorgianni G, Di Bella B, Trimarchi F \& Vermiglio F. Gestational thyroid function abnormalities in conditions of mild iodine deficiency: early screening versus continuous monitoring of maternal thyroid status. European Journal of Endocrinology 2009 160 611-617. (doi:10.1530/EJE-08-0709)

26 Panesar NS, Li CY \& Rogers MS. Reference intervals for thyroid hormones in pregnant Chinese women. Annals of Clinical Biochemistry 200138 329-332. (doi:10.1258/ 0004563011900830)

27 Haddow JE, Knight GJ. Palomaki GE, McClain MR \& Pulkkinen AJ. The reference range and within-person variability of thyroid stimulating hormone during the first and second trimesters of pregnancy. Journal of Medical Screening 200411 170-174. (doi:10.1258/0969141042467340)

28 Lambert-Messerlian G, McClain M, Haddow JE, Palomaki GE, Canick JA, Cleary-Goldman J, Malone FD, Porter TF, Nyberg DA, 
Bernstein P, D'Alton ME \& for the FaSTER Research Consortium First- and second-trimester thyroid hormone reference data in pregnant women: a FaSTER (First- and Second-Trimester Evaluation of Risk for aneuploidy) Research Consortium study. American Journal of Obstetrics and Gynecology 2008199 62.e1-62.e6. (doi:10.1016/j.ajog.2007.12.003)

29 Boas M, Forman JL, Juul A, Feldt-Rasmussen U, Skakkebaek NE, Hilsted L, Chellakooty M, Larsen T, Larsen JF, Petersen JH \& Main KM. Narrow intra-individual variation of maternal thyroid function in pregnancy based on a longitudinal study on 132 women. European Journal of Endocrinology 2009161 903-910. (doi:10.1530/EJE-09-0579)
30 Zamrazil V, Bilek R, Cerovska J \& Delange F. The elimination of iodine deficiency in the Czech Republic: the steps toward success. Thyroid 200414 49-56. (doi:10.1089/105072504322783849)

31 Dvorakova M, Bilek R, Cerovska J, Hill M, Novak Z, Vavrejnova V, Vlcek P, Vrbiková J \& Zamrazil V. The volumes of the thyroid gland in adults aged 18-65 years in the Czech Republic - determination of the norms. Vnitřní lékařství 200652 57-63.

Received 14 July 2010

Accepted 3 August 2010 